\title{
Black rhino in South Luangwa National Park: their distribution and future protection
}

\author{
N. Leader Williams
}

It became clear in 1979 that commercial poaching was drastically reducing the numbers of rhino in Luangwa Valley and the Zambian Government, through its National Parks and Wildlife Service (NPWS) and the World Wildlife Fund, responded by setting up Save the Rhino Trust (SRT). Neither past nor present numbers and distribution of these animals were sufficiently known to provide a baseline for monitoring the effects of the poaching and the author carried out research on behalf of NPWS and SRT during 1981-82 to assess the status of the rhinos in the Luangwa Valley; FFPS was among the financial supporters of the work. Here he describes the problems that the task presented and the development of a technique that will provide a way of assessing the effectiveness of future anti-poaching operations. The study's findings that 72 per cent of rhinos that die in Luangwa do so from poachers' bullets led to a recommendation for a change in patrol policy; this was adopted by SRT in 1983 and its success is being monitored.

Black rhinoceros Diceros bicomis are exceedingly hard to count accurately: they live at low densities in thick bush and are mainly solitary and nocturnal. However, as black rhinos continue to decline throughout their present range because of excessive poaching, it becomes increasingly necessary to attempt to define the numbers and distribution of the species in their major strongholds. One such is Zambia's Luangwa Valley (Figure 1), a wildlife area of some $63,000 \mathrm{sq} \mathrm{km}$ containing four national parks (NPs) and seven game management areas (GMAs). An antipoaching unit was formed in the area in 1979 and Black rhino in South Luangwa National Park a research effort was set up later in 1981 to investigate aspects of the ecology of rhino relevant to their protection, and has concentrated upon the largest of Luangwa's national parks. This paper first describes the background to the present research and the reasons for developing a technique to assess rhino distribution; second, it presents results arising from this research up to December 1982 and makes recommendations for future protection of rhinos in Luangwa Valley.

\section{Background}

Assessment of black rhino numbers and distribution in other areas of Africa have included the following:

(1) Total counts of known individuals. Within smaller parks and reserves total counts and distribution of rhino have been obtained by compiling a catalogue of known individuals, for example Ngorongoro Crater (Klingel and Klingel, 1966), Olduvai Gorge (Goddard, 1967a), Nairobi (Hamilton and King, 1969), Masai Mara (Mukinya, 1973) and Amboseli (Westem and Sindiyo, 1972) in East Africa; Hluhluwe and Umfolozi (Hitchins, 1968) in South Africa. While very accurate, this method is time consuming: none of the areas surveyed exceeded $1000 \mathrm{sq} \mathrm{km}$ and none of the studies were completed in less than one year.

(2) Aerial census. Rhino are notoriously difficult to count from the air (Goddard, 1967b). Whilst crude estimates with a standard error can be derived from numbers of rhino sighted within transects, such surveys provide gross underestimates of rhino numbers. Crude estimates are therefore 'corrected' by factors varying from 1.5 
to 7 , which are usually based on evidence provided by Goddard (1967b) and are less commonly specific to the area being surveyed (Western, 1982; Borner, 1983). In spite of their considerable inaccuracies, aerial censuses have so far provided the only realistic way to make some sort of estimate of rhino numbers in large areas, for example Tsavo (Goddard, 1969). However, repeated counts of black rhino in large areas are of doubtful use in describing population trends because the errors are so large, for example, counts of 1976 and 1981 in Selous (Borner, 1983). Again, the only park where repeated aerial counts have been of use in following population trends with any accuracy has been in the small area and rapidly declining population of Amboseli (Western, 1982).

\section{Zambian perspective}

Previous knowledge of Zambian rhinos was minimal: Sidney $(1965)$ and Ansell $(1969,1975)$ provided information on their former and present distribution, together with 'guestimates' of numbers. An FAO team in the early 1970 s confirmed the importance of the rhino population in Luangwa Valley (Naylor et al., 1973). Their team overflew a $492-\mathrm{km}$ flight path, but did not cover the Luangwa Valley systematically, to record an observed density of 0.1 rhino per sq $\mathrm{km}$. This estimate was corrected by a factor of 4 to give $0 \cdot 4$ rhinos per sq $\mathrm{km}$ which, when multiplied by the total area available to rhinos, gave estimates of $4000-12,000$ rhinos for the whole valley and of around 2800 rhino in the $9050 \mathrm{sq} \mathrm{km}$ South Luangwa NP. Since then, commercial poaching of both rhino and elephant has increased dramatically in the Luangwa Valley, and it is no longer possible to multiply up from a density obtained in a small unsystematic survey to numbers present in the whole area: the rhinos surviving the poachers' predations are probably patchily rather than biologically distributed in pockets of uneven density.

Attention was drawn to the extent to which poaching had made inroads to the Luangwa Valley's rhino and elephant populations by Douglas-Hamilton et al. (1979). They undertook a low intensity ( 3 per cent) multi-species aerial survey which overflew a 20,000 -sq-km census

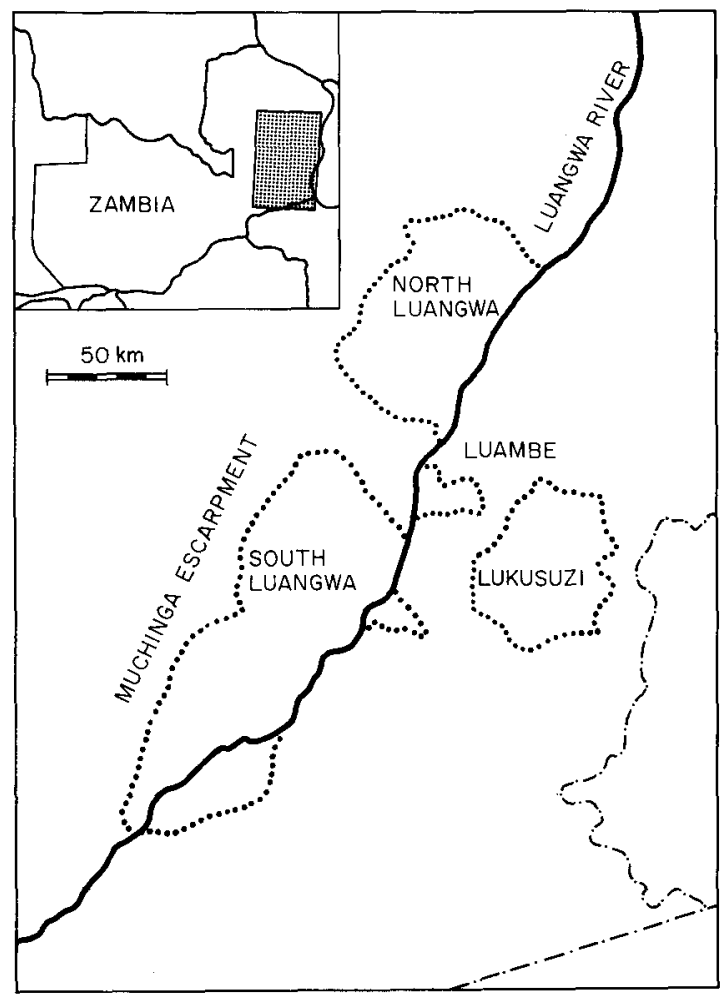

Figure 1. Map showing the location and the national parks of the Luangwa Valley.

zone covering North and South Luangwa NP and Luambe NP plus some adjacent GMA on a 2000 $\mathrm{km}$ flight path and which was intended primarily to count elephants. Only 25 rhinos were seen in the transects, which produced a crude estimate of $867 \pm 250$ rhinos occurring at densities of 0.04 per sq $\mathrm{km}$, a considerable decrease from the crude density figure of 0.1 rhinos per sq $\mathrm{km}$ obtained in 1973. Douglas-Hamilton et al. (1979) adopted a correction factor of 2 , which suggested that there were 1734 rhino in the census zone and perhaps 2500-3500 rhino in the Luangwa Valley. They agreed that this estimate was only a rough indication of the true population and that higher intensity counts were required for rhinos: these were undertaken only in the 212-sq-km Nsefu sector of South Luangwa NP without resorting to any correction factor, and they returned a figure of $66 \pm 29$ rhinos.

It was against this backdrop that the Zambian Government, through NPWS, and WWF agreed Oryx Vol 19 No 1 
to set up SRT in late 1979 to protect rhino and elephant populations within the Luangwa Valley NPs. Since little was known of the ecology of rhino in the area, a research programme was also set up to provide some knowledge upon which to base measures for rhino protection. From the above review, the following points were clear when I made a preliminary visit to Zambia in 1980:

(1) that the large size, woodland habitat and general inaccessibility of the area would pose problems;

(2) that there was no adequate baseline upon which to monitor population trends accurately; the 1973 survey was not systematic, while the 1979 survey was not designed for rhino and was of too low an intensity;

(3) that major sources of error between surveys lie in not knowing what the correct "correction' factor is, those of 4,2 and 0 having been used at various times in Luangwa Valley;

(4) that the aerial surveys had provided no clear idea of the distribution of rhino within different areas of the Luangwa Valley;

(5) that there was no means of assessing the effect of poachers upon the rhino population.

It was thus felt that further aerial surveys to answer the vexing question of "how many are there?' were not worthwhile until densities, distribution and patterns of mortality had been established on the ground, thereby answering the more immediate questions of 'how effective are we in protecting rhinos' and 'which key areas do we protect?' It was planned, therefore, to adopt two approaches when the project began in September 1981:

(1) Intensive research within one area of South Luangwa NP to establish densities of rhino: at the same time to investigate other important aspects of rhino ecology such as food plants eaten, favoured habitats at different seasons, seasonal movements and home range size, and population structure and rate of recruitment. These latter topics are still under investigation and will be reported elsewhere.

(2) Extensive ground-based surveys of rhino distribution and mortality, which form the main subject of this paper.

\section{Methods}

\section{Densities}

An intensive study area, typical of the habitat of the Luangwa Valley and with year round access and that had only been lightly poached, was chosen near Mfuwe in South Luangwa NP. An individual recognition file of rhinos occupying this 200 -sq-km area was built up using methods found successful in East and South Africa. The area has been covered systematically on foot, and over $2000 \mathrm{~km}$ were walked between September 1981 and December 1982 in search of rhinos. In addition, a similar file was built up in the Nsefu sector of South Luangwa NP by N. St John and J. Saxton during the 1981 and 1982 dry seasons.

\section{Distribution}

Rhino are seen infrequently and are hard to enumerate, even on the ground. However, indirect signs of their presence are more commonly encountered. These include middens (communal dunging areas), dungpiles (dung dropped away from middens), tracks and footscrapes (parallel marks where rhinos scrape their hindfeet). An easy system of counting these signs was devised initially within the intensive study area, for subsequent use along routes used by SRT antipoaching patrols. Indirect signs were graded into fresh (less than one day old), recent ( $1-4$ days old) and old (more than 4 days old) categories and counted against distance walked as measured on a pedometer calibrated against a vehicle odometer. These counts were then extended into other areas of South Luangwa NP by N.R.H. Dodds and J.C. Fishwick, who walked $657 \mathrm{~km}$ with SRT patrols during the dry season of 1982. By comparing counts of indirect signs in two areas of known rhino density, it was hoped to determine whether other areas surveyed had similar or lower densities of rhino.

\section{Mortality}

All rhino skulls found by SRT patrols throughout the Luangwa Valley have been collected and the known or estimated year of death recorded. Skulls have been divided into two categories: those known to have been definitely poached, bearing axe-marks on the nose where poachers

Black rhino in South Luangwa National Park 
have cut off the horns (Figure 2); those with intact skulls that died from either natural or unknown causes, this latter category also including an unknown percentage of deaths subsequent to wounding by poachers who were unable to retrieve the horns.

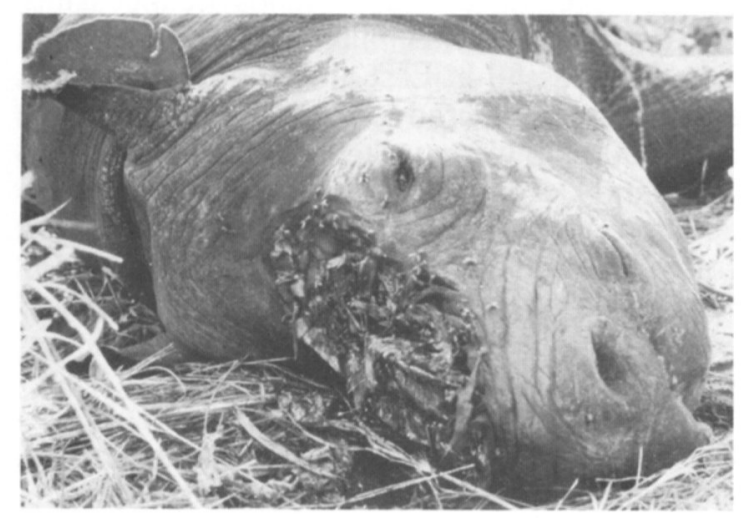

Figure 2. Poached rhino can be recognised from axe marks where homs are removed.

\section{Results and discussion}

\section{Densities}

During September 1981 to December 1982, 237 different sightings of rhino (counting mothers accompanied by their calves as one sighting) were achieved in the Mfuwe study area. From Figure 3 it is clear that a year of survey work was required to be certain that most rhinos in the area had been catalogued, i.e. that no new rhinos were seen amongst the sightings. The survey has shown that 66 adults and 11 calves accompanying their mothers have been present in the 200sq-km study area. The less intensive survey in the Nsefu sector was based on 155 sightings and has shown that a minimum of 37 rhinos occupied the area during 1981/82, an estimate somewhat lower than that made by Douglas-Hamilton et al. (1979) of $66 \pm 29$ rhinos. The densities for these two areas of Luangwa Valley (Table 1) lie in the middle of the range of those recorded in natural populations of East Africa (Goddard, 1969) before commercial poaching became a problem, and are lower than those in the translocated populations of South Africa (Hitchins and Anderson, 1980).

\section{Distribution}

Results from patrols undertaken in seven different areas of South Luangwa NP (Figure 4 ) are summarised in Figure 5 . Counts of rhino middens and dungpiles sighted per $\mathrm{km}$ walked correlated both with the total number of tracks and scrapes and with the number of fresh signs of rhino including sightings in each area.* Middens and dungpiles were the most numerous indirect signs counted and also the easiest to count without halting the patrol. Tracks and scrapes needed to be examined more closely and grading their freshness was more subjective. With only two areas of known density it was not possible to determine which of the indirect signs is the best predictor of rhino density. However, knowledge of the differences in densities between the Mfuwe study area and Nsefu (Table 1), and statistical tests of differences in the frequencies of occurrence of the

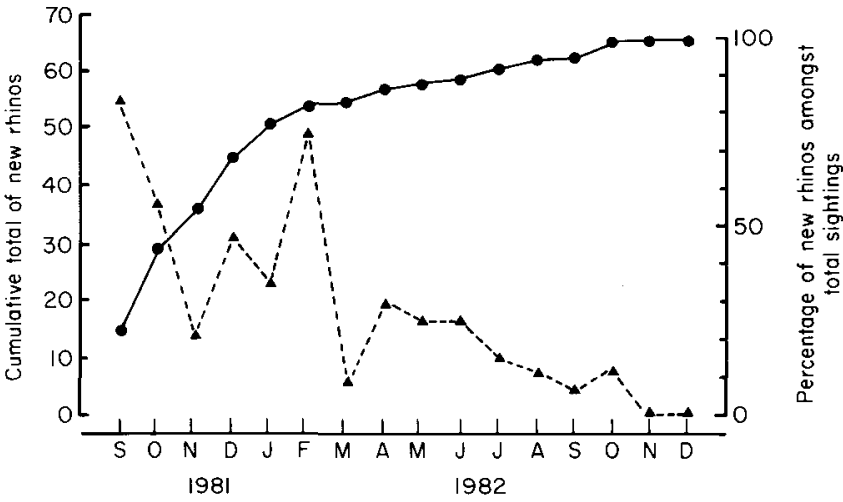

30
Figure 3. Cumulative total of new rhinos, represented by solid line, and percentage of new rhinos amongst total sightings, represented by broken line, observed in the Mfuwe study area during 1981 and 1982. 


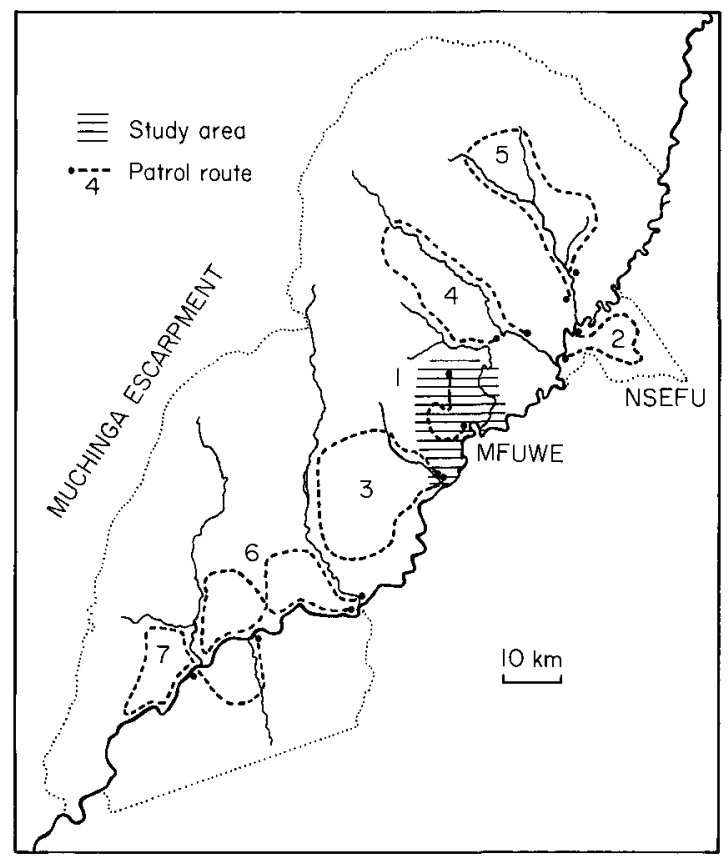

Figure 4. Map showing seven patrol routes taken to assess rhino distribution and the intensive study area in South Luangwa NP.

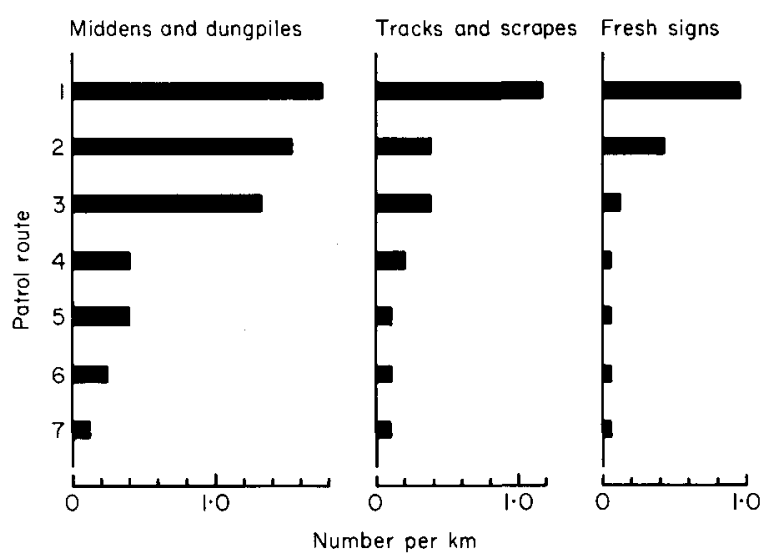

Figure 5. Numbers of middens and dungpiles, tracks and scrapes and fresh signs of rhino seen per $\mathrm{km}$ on seven patrol routes in South Luangwa NP.

* Details of statistical analyses are available on request from the author.

Black rhino in South Luangwa National Park
Table 1. Black rhino densities in Luangwa Valley in 1982

\begin{tabular}{llll}
\hline Area & Adults and calves & $\begin{array}{l}\text { Total area } \\
\text { in sq km }\end{array}$ & $\begin{array}{l}\text { Density per } \\
\text { sq km }\end{array}$ \\
\hline Mfuwe & $66+11$ & 200 & $0 \cdot 4$ \\
Nsefu & $31+6$ & 212 & $0 \cdot 2$ \\
\hline
\end{tabular}

various types of indirect sign* allowed the various areas patrolled to be listed in their order of importance as rhino strongholds as shown in Figure 5.

\section{Mortality}

A total of 88 skulls from rhinos known to have been poached or to have died from natural and unknown causes during 1979 to 1982 have been found by SRT patrols in the NP of Luangwa Valley. There has been no significant decrease* in the numbers of skulls found since 1979 (Figure 6). As importantly there has been no change in the ratio of axed to intact skulls found during 1979 to 1982 . Thus at least 72 per cent of rhinos throughout Luangwa Valley continue to die from poachers' bullets and only 28 per cent die from other causes, which may also include wounding by poachers.

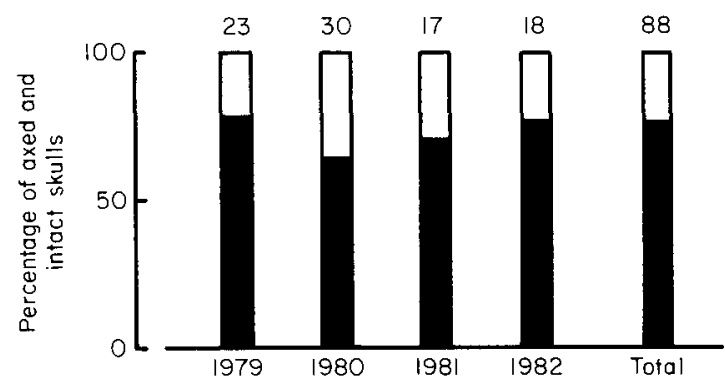

Figure 6. Percentage of axed and intact skulls collected in NP of Luangwa Valley shown with numbers collected from 1979 to 1982; solid bars signify axed skulls and open bars signify intact skulls. 


\section{Conservation}

Luangwa Valley is one of Africa's major black rhino strongholds, both because of its large area of available habitat and of the potential density of rhino in the absence of poachers. However, under present circumstances within Zambia, commercial poaching is a cause for much concern. From the outset of its operations in late 1979, SRT's anti-poaching unit has comprised 22 scouts seconded from NPWS and one or two warden-rangers. Their policy has been to cover the NP of Luangwa Valley (a total of 16,860 sq $\mathrm{km}$ with a density of one scout per $760 \mathrm{sq} \mathrm{km}$ ) and apprehend poachers. From evidence of the numbers of poachers caught and weapons seized (Table 2), it appeared that SRT was having great success. However, the skulls provide more cautionary evidence, for over two-thirds of rhino still die from being poached. In view of the effect that poachers still have on the rhino population, is it time for a change in emphasis?

Table 2. Numbers of poachers caught and weapons seized by SRT in Luangwa Valley from 1979 to 1982 (from Faddy, 1982)

\begin{tabular}{lcc}
\hline Year & Poachers arrested & Weapons seized \\
\hline 1979 & 51 & 7 \\
1980 & 103 & 37 \\
1981 & 111 & 34 \\
1982 & 47 & 24 \\
\hline
\end{tabular}

Clearly efforts must be directed at increasing the protection afforded to rhinos. The effective scout density should be increased such that poaching is prevented, in certain key areas at least. It is apparently insufficient to send patrols into the NPs simply to apprehend poachers, especially if they have already shot several rhinos. If it is not possible greatly to increase SRT funding and staff, it appears that more concem should be directed towards maintaining the integrity of the higher density subpopulations of rhino in key areas. Counts of indirect signs of rhino (Figure 5) clearly delineate the areas of South Luangwa NP that are still worth protecting and those to which less concern should be diverted. The two adjacent areas 32 surrounding patrol routes 1 and 3 (Mfuwe study area and Manze to Panza Rivers) and the Nsefu sector (patrol 2) total some $600 \mathrm{sq} \mathrm{km}$ (Figure 4) and could be better protected by the present staff of SRT at an effective density of one scout per 30 $\mathrm{sq} \mathrm{km}$. If even this still proves insufficient, further retrenchment will have to be considered.

The technique described here to assess rhino distribution is simple and can be used during the course of routine patrolling duties. The scientific basis of the technique could be strengthened by counting indirect signs along fixed transects, but this would require special patrols, extra staff and more time to cover a large area. The present technique, despite the relative inaccuracy of pedometers, has much to recommend its use here and in other extensive areas of rhino habitat in Africa, as a worthwhile means of obtaining information quickly and at little extra cost. Its use in the Luangwa Valley in future years, together with records from rhino skulls, will help assess the effectiveness of anti-poaching operations unfortunately vital to the survival of rhinos.

\section{Recommendation}

The following major recommendation arising from this study was presented to NPWS and SRT early in 1983:

That a change in patrol policy be instituted and that most effort be directed towards preventing poaching of rhinos in small and well defined key areas of South Luangwa NP.

The recommendation has been adopted by SRT and its success will be monitored.

\section{Acknowledgments}

I am grateful to National Parks and Wildlife Service for permission to undertake research and to G.B. Kaweche for his support in initiating the project. The work has been supported by a grant from People's Trust for Endangered Species and FFPS, and by funds raised from commercial companies, organised by Rover (Zambia), Dunlop Zambia and Zambia Oxygen, through Save the Rhino Trust. Scouts and staff of NPWS and SRT are thanked for their help, companionship and enthusiasm in the bush. I also thank N.R.H. Dodds, J.C. Fishwick, J. Saxton and N. St John for help with collection of data and P.S.M. Berry for organising the collection of skulls. Other sponsors and helpers, too numerous to mention individually, are also acknowledged gratefully: their support has been much appreciated.

Oryx Vol 19 No 1 


\section{References}

Ansell, W.F.H. 1969, 1975. The black rhinoceros in Zambia. Oryx, 10, 176-192 and 13, 83-84.

Borner, M. 1983. Selous aerial survey 1981. Afr. Elephant Rhino Gp. Newsl. 1, 7.

Douglas-Hamilton, I., Hillman, A.K.K., Holt, P. and Ansell, P. 1979. Luangwa Valley Elephant, Rhino and Wildlife Survey. Report to IUCN/WWF/NYZS, Nairobi, mimeo.

Faddy, M. 1982. Save the Rhino Trust Limited, Annual Report 1982. SRT, Lusaka, mimeo.

Goddard, J. 1967a. Home range, behaviour and recruitment rates of two black rhinoceros populations. E. Afr. Wildl. J. 5, 133-150.

Goddard, J. 1967b. The validity of censusing black rhinoceros populations from the air. E. Afr. Wildl. J. 5, 18-23.

Goddard, J. 1969. Aerial census of black rhinoceros using stratified random sampling. E. Afr. Wildl. J. 7, 105-114.

Hamilton, P.H. and King, J.M. 1969. The fate of black rhinoceros released in Nairobi National Park. E. Afr. Wildl. J. 7, 73-83.

Hitchins, P.M. 1968. Some preliminary findings on the population structure and status of the black rhinoceros Diceros bicomis in the Hluhluwe Game reserve, Zululand. Lammergeyer 9, 26-28.
Hitchins, P.M. and Anderson, J.L. 1980. Reproduction, population characteristics and management of the black rhinoceros population in the Hluhluwe/Corridor/Umfolozi complex. Report to Natal Parks Board, mimeo.

Klingel, H. and Klingel, U. 1966. The rhinoceroses of Ngorongoro Crater. Oryx 8, 302-306.

Mukinya, J.G. 1973. Density, distribution, population structure and social organisation of the black rhinoceros in Masai Mara game reserve. E. Afr. Wildl. J. 11, 385-400.

Naylor, J.N., Caughley, G.J., Abel, N.O.J. and Liberg, O 1973. Luangwa Valley Conservation and Development Project. Report to UNDP/FAO, Rome, mimeo.

Sidney, J. 1965. The past and present distribution of some African ungulates. Trans. zool. Soc. Lond. 30, 1-397.

Western, D. 1982. Patterns of depletion in a Kenya rhino population and the conservation implications. Biol. Conserv. 24, 147-156.

Western, D. and Sindiyo, D.M. 1972. The status of the Amboseli rhino population. E. Afr. Wildl. J. 10,43-57.

N. Leader-Williams, Large Animal Research Group, 34A Storey's Way, Cambridge, UK.

\section{Abbreviations and acronyms used in this issue of Oryx}

\begin{tabular}{|c|c|c|c|}
\hline AAZPA & $\begin{array}{l}\text { American Association of Zoological } \\
\text { Parks and Aquariums }\end{array}$ & $\begin{array}{l}\text { IWC } \\
\text { MAFF }\end{array}$ & $\begin{array}{l}\text { International Whaling Commission } \\
\text { Ministry of Agriculture, Fisheries and }\end{array}$ \\
\hline $\mathrm{ACF}$ & Australian Conservation Foundation & & $\begin{array}{l}\text { Food } \\
\text { Fod }\end{array}$ \\
\hline CITES & $\begin{array}{l}\text { Convention on International Trade in } \\
\text { Endangered Species of Wild Fauna }\end{array}$ & $\begin{array}{l}\text { MGP } \\
\text { NCC } \\
\text { RSPR }\end{array}$ & $\begin{array}{l}\text { Mountain Gorilla Project } \\
\text { Nature Conservancy Council }\end{array}$ \\
\hline ICBP & International Council for Bird & & $\begin{array}{l}\text { Royal soclety for the Protection of } \\
\text { Birds }\end{array}$ \\
\hline & $\begin{array}{l}\text { Preservation } \\
\text { Intion }\end{array}$ & SSC & $\begin{array}{l}\text { Species Survival Commission } \\
\text { Site of Snecial Scientific Interest }\end{array}$ \\
\hline IFAW & $\begin{array}{l}\text { International Crane Foundation } \\
\text { International Fund for Animal }\end{array}$ & WWF & World Wildlife Fund \\
\hline IUCN & $\begin{array}{l}\text { International Union for Conservation } \\
\text { of Nature and Natural Resources }\end{array}$ & & \\
\hline
\end{tabular}

